\title{
Enhancing Critical Awareness through Socratic Pedagogy
}

\author{
Seher Balbay a* \\ a Middle East Technical University, Ankara, Turkey
}

Received 17 September 2019 | Received in revised form 28 October 2019 | Accepted 06 November 2019

\author{
APA Citation: \\ Balbay, S. (2019). Enhancing critical awareness through Socratic pedagogy. Eurasian Journal of Applied Linguistics, \\ 5(3),515-536. Doi: 10.32601/ejal.651348
}

\begin{abstract}
Socratic pedagogy is an approach to teaching through questioning mainstream practices without being judgmental in an effort to understand, empathize and reach more objective conclusions about reality. This study explores the effects of its use on student teachers' critical awareness skills during their participation in a Spoken English course given at a Foreign Language Education Department in Turkey. This qualitative study was conducted with freshman students and the intervention lasted one academic year. Individual and focus group interviews, and observation notes based on student performance in class were used as data collection tools. The results clearly indicate the development of students' critical awareness of political, economic and culture-related issues regarding language teaching settings, and they generated deeper insight to multiple aspects of teaching English. Students displayed an understanding of the consequences of political decisions as well as the economic dimensions of educational commitments, and expressed a positive attitude towards cultural diversity after a yearlong Socratic pedagogy intervention.
\end{abstract}

(C) 2019 EJAL \& the Authors. Published by Eurasian Journal of Applied Linguistics (EJAL). This is an open-access article distributed under the terms and conditions of the Creative Commons Attribution license (CC BY-NC-ND) (http://creativecommons.org/licenses/by-nc-nd/4.0/).

Keywords: Socratic pedagogy, critical awareness, Spoken English, diasadvantaged groups, cooperative learning

\section{Introduction}

To be able to discuss the benefits of an educational approach to language teaching, it makes sense to look back in history and explore how structured learning and teaching at schools started, what was meant by education in earlier times, and how teaching was shaped by the economic, political and cultural forces of the period. We also need to take care how such investigations are approached, particularly when we find ourselves taking issue with mainstream culture, past and present. Fortunately, this is not a new problem and a reliable method of making such criticisms dates back to $400 \mathrm{BC}$ and the times of Ancient Greece. Socrates is known not only as a philosopher who influenced his successors, but as one of the first 'teachers' whose methodology has been the topic of numerous books and articles on pedagogy and ethics. It is thanks to his students, mostly Plato and Xenophon that we today are enlightened by his unprecedented ways

\footnotetext{
* Corresponding Author. Tel.: +90-505-257-9208

E-mail address: seherb@metu.edu.tr
} 
of thinking and questioning (Bartlett, 2008). Socrates has been read and widely discussed and favored even in modern day classrooms. His teaching method made use of any content, to focus on questioning everything that is assumed to be known, essentially promoting critical thinking in a systematic and educative way.

Later during the Renaissance and in today's modern world, we have witnessed shifts in educational trends to encourage deeper insight into phenomena considering different perspectives, and towards trying to rid our minds of prejudice and assumptions. The recent shift is apparent in the curriculum documents of many developed countries where significant resources continue to be invested in education. While 'school' is still infamous for limiting free thinking, and free expression of ideas, ideally it is a safe space where we can better understand, empathize, tolerate and help each other when in every sense broadening our knowledge of the world and ourselves.

Language classes offer rich opportunities to enhance critical awareness, especially in advanced level courses which tend to embrace a wide range of topics. It follows that in the training of language teachers, a pre-step should be to enhance their critical awareness, vision and consequently future performance. In this the cascading effect of teachers is undeniable. Thus, it is a promising stance to integrate teaching methods in teacher training programs which would support the discussion of ideas in particular settings and consider the background of specific contexts. Furthermore, it is known that novice teachers need to develop a significant range of reflection-based critical thinking processes to construct their professional identity and be able to consider the historical and cultural conditions they may encounter (Antonek, McCormick, \& Donato, 1997). Thus, any teacher training program should implement teaching practices that enable student teachers to cope with the economic, cultural and political realities of our times.

One way of essentially inviting people to doubt their assumptions on critical issues that relate to how a language is taught is to expose theoretical concepts to real life and to question routine implications. Such an approach can engender broad reaching discussion of critical pedagogical content. Known as a Socratic seminar, such discourse lends itself to any class where cooperative debate is crucial. Especially in second language classes, Socratic seminars have proven to be significantly beneficial in helping students to develop plausible expressions of support for their arguments and to reach meaningful consensus.

\section{Literature review}

\subsection{Socratic Pedagogy}

Arendt (1958) claims that our sense of reality depends on sharing the world with others (as cited in Borren, 2013, p. 233). Therefore, in school life too, when discussing our sense of reality, we should be collaborative and cooperative. Simply put, this practice dates back to Socrates's methods referred to in the Platonic dialogues (Boghossian, 2006). It denies either-or propositions false dichotomies, and promotes and believes in the merit of questioning all assumptions. Although its origins were 
burgeoning in $400 \mathrm{BC}$, it is valued in postmodernist approaches that seek multiple interpretations and the truths of subjective thoughts with the constructivist admission that "no one perspective is 'more valid' than any other perspective." (Boghossian, 2006, p. 715). The role of the teacher in Socratic Pedagogy is to enable a systematized question and answer process with the intention of engaging students in a dialogue through sustained and dynamic inquiry in which the students are the active participants in their own learning (Boghossian, 2002). The teacher is the facilitator of dialogues in the group not by interfering in the dialogues but by posing the right questions at the right time.

The Socratic seminar is a distinctly unique format of classroom discussion. It may be time consuming for the teacher to arrange and explain, yet utilized effectively, it is an opportunity for students to spend effort to reach a deeper insight having open-mindedly exposed themselves to different perspectives on the subject matter. In the Socratic Method there is no room for parroting the teacher's lectures, to the contrary creative thought and imagination are valued and encouraged (Bhaerman, 1970). The major difference in this form of a debate is that the ultimate goal is not to refute the other party but to reach an understanding of the possibly opposing ideas.

The requirement to be engaged in a Socratic seminar is listening to the speakers attentively. Students think critically about the subject matter and are expected to express their ideas with civility rather than with an aggressive persuading tone. Usually conducted in a circular seating arrangement, the seminar aims to enable students to easily articulate their thoughts on the thoughts of others.

The ideal content material should have multiple perspectives on a topic. Both students and teacher prepare critical questions which can be projected on a screen visible to the circle. A communal spirit is central to the progress of the discussion, that is, students respectfully react to interpretations and different perspectives to 'grow' from the others' responses. In some practices there can be remedial support from students seated in a surrounding circle of the inside circle to send written notes to their partner in the inside circle who is actively engaged in the discussion (Filkins, n.d.). This 'feeding in' to the inside circle is to help less verbal members participate in the discussion with the idea and language support they receive. The two circles switch places after a certain period of time so that the outside circle now sits in the inside circle and precedes the discussion. Students are responsible for noting and redressing imbalances in the discussion by helping relatively passive members to join by addressing questions to them. In this way no participant can dominate the discussion and swiftness or assertiveness finds no weight in discourse on culture, command of language, gender, and so on, as everyone's ideas are valued, hence entitled to be heard. It is not uncommon that a quiet student brings a thought provoking perspective and changes the flow of the discussion all together. Students are introduced to the rationale and the philosophy behind the format of the task beforehand going over some guiding questions. The six types of Socratic questions that students are encouraged to ask are detailed below. 
Table 1. R.W. Paul's six types of Socratic questions (“The six types of Socratic questions", n.d.).

\begin{tabular}{|c|c|}
\hline \multirow{2}{*}{ 1. Questions for clarification: } & Why do you say that? \\
\hline & How does this relate to our discussion? \\
\hline \multirow{2}{*}{ 2. Questions that probe assumptions: } & What could we assume instead? \\
\hline & How can you verify or disprove that assumption? \\
\hline \multirow{3}{*}{$\begin{array}{l}\text { 3. Questions that probe reasons and } \\
\text { evidence: }\end{array}$} & What would be an example? \\
\hline & What is.... analogous to? \\
\hline & What do you think causes to happen...? Why? \\
\hline \multirow{7}{*}{$\begin{array}{l}\text { 4. Questions about viewpoints and } \\
\text { perspectives: }\end{array}$} & What would be an alternative? \\
\hline & What is another way to look at it? \\
\hline & Would you explain why it is necessary or beneficial, and who benefits? \\
\hline & Why is the best? \\
\hline & What are the strengths and weaknesses of...? \\
\hline & How are... and ...similar? \\
\hline & What is a counterargument for...? \\
\hline \multirow{5}{*}{$\begin{array}{l}\text { 5. Questions that probe implications } \\
\text { and consequences: }\end{array}$} & What generalizations can you make? \\
\hline & What are the consequences of that assumption? \\
\hline & What are you implying? \\
\hline & How does...affect...? \\
\hline & How does...tie in with what we learned before? \\
\hline \multirow{4}{*}{ 6. Questions about the question: } & What was the point of this question? \\
\hline & Why do you think I asked this question? \\
\hline & What does...mean? \\
\hline & How does...apply to everyday life? \\
\hline
\end{tabular}

The Socratic method creates a sense of belonging in a community among its participants as they grow closer to each other during the discussions since it is based on the vicarious feature of being a human. This feeling of a community might sometimes last only during the period of the discussion (Altorf, 2016), or it may continue and become the class culture and may manifest itself even when there is no formal seminar being held. In the Socratic method participants try to understand each other. This is the ultimate distinction between a debate and a Socratic seminar. In the latter, the participants do not try to refute the supposedly false claims of the other party, prove them wrong, unsounded or inconsistent as a challenge in a shouting match. In such a comfort zone it is much easier for students with high anxiety levels to participate in the discussions. In fact, one of the most required skills for a language teacher is the spontaneous speaking skills practiced during the seminars since they will be making decisions instantly and acting accordingly when they are teaching even when they stick to a detailed lesson plan (Vanci Osam \& Balbay, 2001).

The aim in Socratic dialogue is mutual understanding. Nelson (2004) explains this approach to teaching by stating that "the art of teaching is making philosophers" out of students (Nelson, 2004, p. 126). The participants are determined not to offend each other.

Reconciliation or rapprochement is not required either, but is desirable. The rationale of dialogue is that participants catch a glimpse of others' truth. The participants are 
asked to relate personal experience to the dialogue. Altorf $(2005$, p. 5) calls the participants in the Socratic dialogue 'midwifes' of each other because they help each other through interventions.

The use of Socratic pedagogy in contemporary education is usually to teach critical thinking (Schwarze \& Lape, 2000) with cooperation and dialogue. Ruthless questioning is seen as a critical thinking exercise. Yet, another requirement of a Socratic method, which is putting oneself in the position of the other, contributes to critical thinking while it still requires questioning. This is the main reason the method is not used only in higher education, but also in institutions such as prisons or simply in the living rooms of families.

\subsection{Socratic approach in teacher education}

The content of higher education offered at universities to teachers-to-be has gone through major changes with the effect of new research and theories in psychology and sociology. Yet, social and political factors are also major determining factors in teacher training programs. Language teacher education programs in Turkey were subject to various recent changes in 1997, 2005, 2012 and again in 2018 (Kırkgöz, 2017; Kırkgöz, Çelik, \& Arıkan, 2016). These changes standardized undergraduate programs for language teacher training across universities, and more emphasis was placed on education, teaching and methodology-related courses than literature and linguistics, and in the most recent changes, more elective courses are on offer. The freshman courses, though, remain mostly concerned with language proficiency and the acquisition of skills in terms of grammar, reading and writing, speaking and listening. While it is common in most other undergraduate studies in Turkey to observe the inclusion of an introductory course to the field, no such introduction has been thought to be warranted that would expose students to the realities and basic concepts of being a language teacher. Thus, no specific or standardized approach exists supporting them to develop their insights as to what being a language teacher entails (Balbay, Pamuk, Temir, \& Dogan, 2018). On the face of it, freshman students in Turkey are simply not asked to vision themselves as teachers and discuss issues directly relevant to language teaching. On the other hand, while the content of the first year proficiency courses has seemingly continued this tradition, the objectives of the language proficiency courses cover language skills which provide space for the discussion of language teacher-related content. The Spoken English courses offered in the first year of English language teaching programs cover such topics as learning a second language, teaching a second language, language acquisition theories, and methods. Thus, the actual practice in state or private schools, the time and materials or funding allocated to language teaching, individual differences in teaching and learning can be explored during the first year. Education related critical content can be readily integrated in the Spoken English courses so that trainee teachers can start envisioning themselves as teachers with the contribution of the critical content elaborated. Hence, students' teacher identity can start developing with thoughts triggered during discourse on situated and contextualized power relationships, inequalities and oppressed groups in educational 
settings either for students' individual dispositional characteristics, or for their ethnic, religious, cultural or socio-economical background.

Mayer (1986) suggests that critical awareness develops when students are provided with opportunities where they can engage with the subject matter. In the case of the present study, this subject matter is education and language education related content. He further elaborates that conceptual level information can become meaningful if related to everyday events, in the case of the present study, and pedagogical content should be related to real life teaching circumstances.

A growing body of relevant literature advocates the broadening of pre-service teachers' understanding of teachers' work and professional role (Valli, 1997). Student teachers' beliefs and experiences, their perception of what is expected in a particular context affect their teaching (Beltman, Glass, Dinham, Chalk, \& Nguyen, 2015). Realities of school life should be touched upon especially in the initial teacher preparation programs for future teachers to start growing and developing the strategic competences they need to deal with the possible problems they face (Gratch, 2001; Kelchtermans \& Ballet, 2002). Brott and Kajs (2001) also support this idea. They claim that the individual maturation process of future teachers begins during the early years of the teacher preparation stage.

While much discourse on teacher identity has been focused on its formation during beginning teaching and throughout a teacher's career, much less has been researched on the subject during the early years of teacher preparation, and even less on the extent of the changes in teacher identity that occur between entry to exit points of pre-service preparation. (Chong, Low, \& Goh, 2011, p. 35)

FLE students bring with them a set of beliefs that constitute their emerging sense of teacher identity which has been influenced and molded by their prior experiences as pupils and their observations of their own teachers. Spoken English courses offered in Foreign Language Education departments in Turkey naturally lend themselves to accommodate such content.

\subsection{Critical Awareness}

Critical awareness bears importance in this research since the methodology used in the intervention is based on developing critical awareness, the ability to process critical thinking skills that is reasoning by abstaining from narrow and subjective perspectives when reflecting on observed and experienced phenomena. Critical awareness requires being aware of logical fallacies that hinder one's reasoning. It bears importance especially when one is in the position to resolve conflicts. What is indispensable for critical awareness is understanding one's self and understanding the world with a multi-dimensional perspective that is considering social, cultural, political, historical and ideological aspects of events. Such content is generated when "there are maximum opportunities for students to become engaged in the subject-matter and when there is a constantly reinforced link between the conceptual level of analysis [...] grounded at the level of everyday relevance" (Mayer, 1986, p.249). As Mayer states, critical 
awareness needs to relate abstract concepts to situated and contextualized real life facts when reflecting on subject-matter. Beltman similarly explains that "critical awareness is shaped by multiple personal and contextual factors, these factors interact in a reciprocal and dynamic way; and so identity is continually reshaped over the life of an individual" (Beltman et. al, 2015).

In the 1990s ESL/EFL research adopted the post structural perspective which does not detach language from its context and does not categorize the use of language according to a community which is distinctly different from others in terms of its cultural, historical, social and political background. With the poststructuralist approach language teaching studies had a more critical frame of reference of identity, immigrant learners, gender, and critical discourse situated in social, cultural and political contexts (McNamara, 2012). Thus, the aim of education and the intention to improve educational settings, methods, and approaches have become more meaningful and teachers' roles have been discussed with a different perspective. Broadly speaking, the teachers' role is to help contribute the world to improve life conditions (Crawford, 1978). Critical awareness development needs the student to burgeon an insight about how the world around them functions, employing a variety of skills to see different aspects of an issue. Educational theorist Paulo Freire's (2005, p. 25) popular term "critical consciousness" is a key to understand this awareness. Freire defines critical consciousness as a "sociopolitical educative tool that engages learners in questioning the nature of their historical and social situation." It is considered to be a communitybased learning method. The term he coined, 'conscientization', refers to developing a perception of social and political contradictions to enhance an in-depth understanding of the world, which teachers among all other professions should possess. Another terminology associated with the Freirean approach to education is 'banking education', which refers to traditional, standardized, formal and mainstream education in which the role of the teacher is to transfer the contents of their mind to students (Bartolome, 1994). Freire distinguishes between banking education and transformative education that seeks to support students' personal and political development through dialogue with the teacher on real-world relevance of class content with the intent of acting on the world (Crookes \& Lehner, 1998). This is an approach that fundamentally requires our educators to refrain from imposing a standardized moral philosophy.

Preparing students to be critical thinkers from the word go would broaden their perspectives over time as they endeavor to situate education in the diverse sociocultural contexts they are likely to encounter. Essentially the teacher brings a context where trainees embark on practices that will frame and inform their professional vision. A reflection oriented approach is thought necessary for trainee teachers to establish connections between their prior experience and knowledge and situations in which they will teach. For this purpose, "teacher education programs have shifted their emphasis from transmission-oriented to a constructivist approach.” (Lee, 2007, p. 321). In this way students gain self-deducing knowledge as they glean insights into education and language acquisition in the actual contexts that teaching and learning take place. The teacher looks for opportunities to reduce themselves from being the focus, gradually 
even to the extent that sometimes they can be considered "redundant" to the interaction unfolding (Lee, 2007, p. 328). Such a task design that promotes critical awareness by creating an atmosphere of discussion of educational issues from multiple aspects is inherent in Socratic Seminars. Discovering reality or developing an insight into one's own reality through inquiry and reflection in dialectic discussions is of paramount importance to the process of how pre-service teachers go about constructing, reconstructing, and deconstructing their own ways of being and feeling like a teacher.

\section{Research design}

The researcher employed critical research methods and reporting to fully understand changes in student cognition, also accepting that it is a plausible choice not to detach a particular feature and measure it with objective scales. Critical approach questions separation of constructs (Pennycook, 1994). Critical research methods "situate research in the social context to consider how knowledge is shaped by the values of human agents and communities" (Chapelle \& Duff, p. 173). Value changes in student interviews can best be identified by deep content analysis considering the context of the research.

Critical Theory has been very influential in the design of the present study because it situates the data in the context of the research and adheres meaning to the findings in the research circumstances considering the historical and cultural background of the participants and the researcher (Morrow \& Brown, 1994). Throughout the research intervention and the interviews, questions were asked to interpret the meanings of social life and critiquing the society and envisioning new possibilities. In this sense, the methodology of the present study resembles that of an ethnographic study because it focuses on the changes in people's thoughts and encourages the participants to "examine the conditions of their existence" (Madison, 2005).

Qualitative data collection and analysis methods were used in this study to answer the research question below:

RQ: What is the impact of the Socratic approach in Spoken English courses on students' critical awareness?

Participants were interviewed twice, once at the beginning and once at the end of the 2018-2019 Academic Year. Both sets of interview questions are shown in Appendix. The researcher kept observation notes on the intervention by referring to the videotaped seminars. The transcriptions of the interviews and the observation notes were analyzed on the qualitative data analysis program MAXQDA 2018 to reach recurring themes. Sample transcriptions were also coded by another researcher, and mismatches were discussed with the researcher to be able to reach a common understanding on the codes for inter-rater reliability. The time line of the data collection can be seen in figure 1 . 


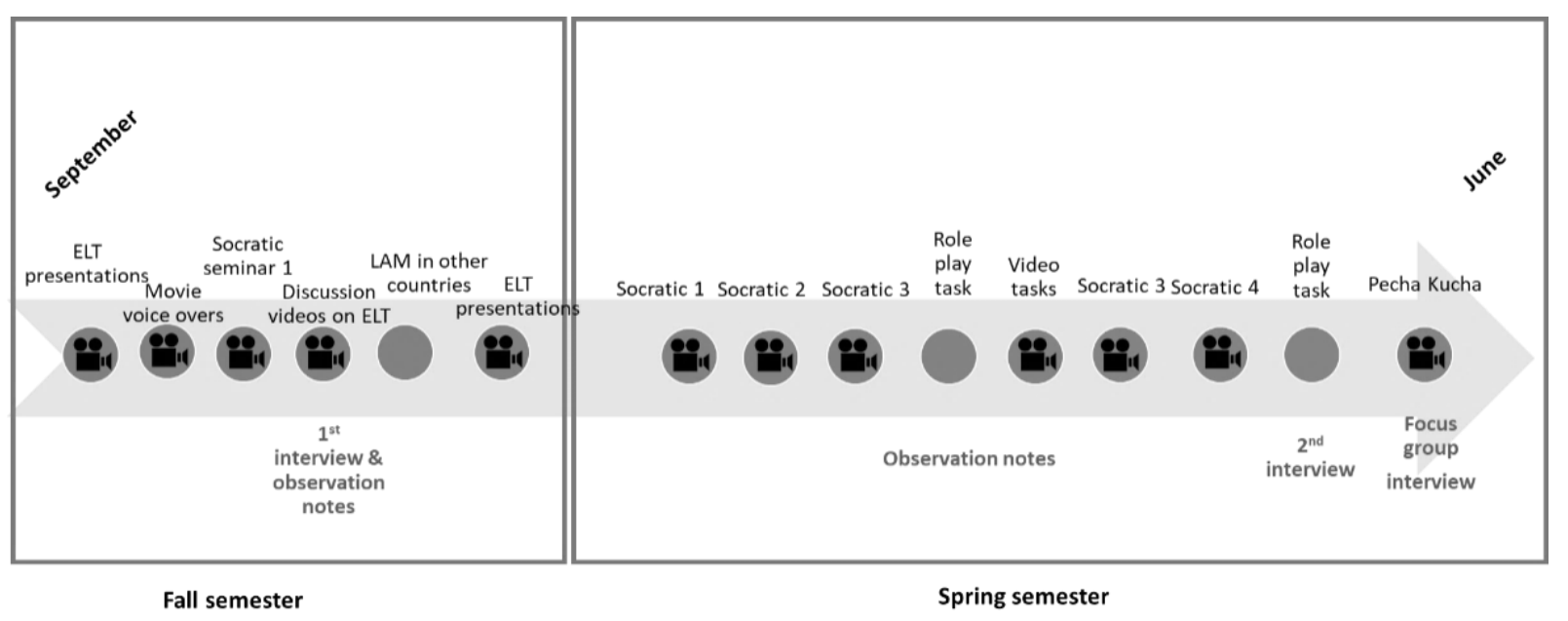

Figure 1. Intervention

\subsection{Participants}

All the participants were freshman year students taking the Spoken English course in a Foreign Language Education program. Among the 22 participants there were one Russian, one South Korean, one Turkish American and one Uzbek student. 13 participants are graduates of Anatolian High Schools which offer a relatively more intense language education program compared to regular state schools in Turkey. 6 of them are graduates of private schools. One participant studied at a state high school, one at a Social Sciences High School, and one at a vocational high school. Only 3 attended the English language preparatory year at the School of Foreign Languages before they started studying at the Foreign Language Education Department.

\subsection{Intervention}

The participants engaged in tasks that focused on critical awareness-oriented content integration in Spoken English courses in different formats over one academic year (6 months). Ennis (1989) categorizes three main methods to trigger the development of critical thinking: the general approach, where critical thinking is taught separately, the infused instruction, where skills are infused in the content of the course, and the immersion approach which is a mixture of the two. In the present study, no content had been specified by the Higher Education Council or the Foreign Language Education Department because Spoken English is a skill-based course for ELT students. When dwelling on content material that focuses on critical issues in educational institutions, that is, integrating critical content in the course, students were not made explicitly aware of the intention to develop their critical awareness, and thus, the infused approach was adapted throughout the academic year the research lasted.

The tasks that students were actively engaged in critical thinking integrating pedagogical content varied. Most of the tasks in Spoken English courses I and II 
consisted of Socratic Seminars on controversial education and language educationrelated issues including topics such as being native-nonnative teachers of English, gender discrimination, racist practices, standardized teaching styles, assessment and so on. While mini presentations on major concepts and researchers in ELT and thought leaders in education, and education in Turkey were assigned as presentation or role play topics, The Socratic Seminars were designed with the intention of effectively integrating critical content with the course. In these civilized cooperative discussions, the aim was not to refute an opposing party but to try to understand and empathize with different perspectives of class mates from various diverse educational and cultural backgrounds, so as to reach a deeper understanding of each other's' point of view by situating differences in the contexts they took place. In the Socratic Method, "occasional resource people and audiovisuals resources are utilized when the need arises" (Bhaerman, 1970, p. 127), thus prior to the seminars students were assigned thoughtprovoking videos about critical pedagogical content, such as moving success stories of teachers in less privileged areas in Turkey and in the world, some influential TED talks, some articles about the educational system and its history especially in Turkey. In some sessions guest experts were hosted to bring up, discuss extensively and cover issues related to critical pedagogical content, such as special needs students or ethnic minority students and colleagues active in education and language education. Some of the topics discussed in the Socratic seminars are as follows: adapting to the school system when it doesn't fit you, cultural bias, unfair treatment of 'otherized' groups, defects of traditional education, administration-monitoring need and relationship, engaging lower income students with academics, rewards-punishment, no child left behind, L2 teacher- agent for linguistic imperialism, high stakes testing being unfair and reliable, idealistic teachers from Turkey and the rest of the world who made a change in difficult circumstances with limited funding and limiting cultural norms.

\section{Results}

The participants' responses to interview questions revealed differences between the first interviews conducted at the beginning and end of the academic year mainly in three recurring themes. The participants were asked to make comments with references to specific cases about the significance of political decisions on education. The references were about English language teaching policies, that they depend on the ruling party and their policies, the importance and place of economical possibilities in creating a major change in education and English language, and the role of respecting and valuing diverse cultures equally to avoid favoring the mainstream culture, to avoid disregarding, devaluing and discriminating against the different ethnic minority cultures, or the practices of otherised unrecognized groups.

The most frequently referred to themes in the interviews and the observation notes were about political decisions and their consequences on education in general in Turkey and on English language teaching practices at state schools, private schools, and at English medium instruction universities. 
Table 2. Codes for the critical awareness themes in interviews, observation notes

\begin{tabular}{lcc}
\hline Critical awareness in : & Number of participants who referred to the code & Number of mentions \\
\hline Education and Politics & 9 & 21 \\
Education and Economics & 4 & 4 \\
Education and Cultural Diversity & 8 & 14 \\
\hline
\end{tabular}

\subsection{Critical awareness in Education and Politics}

The interviews and observation notes conducted before the intervention did not provide comprehensive data as to the participants making connections between politics and education. In the first interviews, the participants made references to a professional life that was full of unpredicted and vague working conditions. Their goals were not clear, or not clearly expressed, and the expressions they used defining their role as a social change agent reflected despair, rather than hope. Yet, no matter how unclear, vague or hopeless the participants sounded during the interviews they made overall comments about the role of English language teacher in a teaching context considering multiple aspects. The participants drew conclusions depending on the observations they had in their previous educational background. While most of the participants claimed that politics does not have a place in education, the participants who could relate politics to education made comments on how frequently the standardized formal state-funded mandatory education system in Turkey kept changing every 3-4 years also affecting the placement exams which reflects itself in the teaching of English language course depending on whether English is tested or not and if tested, what the percentage of English language questions would be in the overall grade point or exam result calculations. Before the intervention, the perception of the participants most depended on their personal experience and did not involve comments on 'seeing the big picture' as one of the participants later, in the second interviews stated. After students had been exposed to, and actively engaged in a series of Socratic seminars based on education related videos of mostly success stories from different parts of the world, including Turkey, the participants made detailed comments as to how politics is and will always be in a reciprocal relationship with education. One of the participants' comments are as follows:

\footnotetext{
I believe that the dominant ideology affects everything and that includes foreign language education. First, there is the efficiency of the education: If an authority wants to indoctrinate its citizens, topics that are actually useful in real life will not be a priority, and there won't be an effort to improve the efficiency of the teaching time. While it may seem unrealistic at first glance; some governments care more about indoctrination than improvement in order to abuse the system of democracy keep their positions, and reducing the efficiency of foreign language education while also acting as if they're trying to improve it makes it a lot easier for them to do so. Likewise, a humanist authority would do its best to improve education and reduce indoctrination.
}

The above students' comments were specific, displaying their analysis and understanding of how political decisions can have direct and immediate consequences 
in education. Another student said that class difference in society is clear to the naked eye especially when one starts school. Even though education is free in Turkey once you see a teacher asking students' their parents' occupations, and treating them accordingly, you realize that there is discrimination at school even though it is not necessarily based on your ethnic background or religion. "Discrimination is rooted in the political stance of the ruling governments, teachers see themselves as representatives of the state and reflect their ideology without any hesitation, without a questioning attitude." Another participant stated that although it seems as though course content at schools do not seem to change with changing ruling government when the content is predetermined by the Ministry of Education teachers feel restrained, hence they become less passionate about teaching the content of their courses. In a chain reaction, students lose interest in such courses.

Similarly, another response to the interviews conducted at the end of the intervention period reveals how aware the participants have become on critical issues when discussing the relation between education and top-down political decisions.

The schools that I attended so far in Turkey have been representatives of certain ideologies and aimed at multiplying followers of their ideologies. Such ideologies can influence the way we think, the way we rationalize, the subjects and concepts we give more importance to over the others (prioritization), our definition of purpose, and etc.

Yet another participant referred to the dominant ideology being imposed on schools by political decisions but also considered it as a unifying culture that would make the people of a country feel like a nation.

Still supporting the importance of the relations between politics and education another participant stated:

As governments are created for a specific agenda that favors their kind over the other, it is simply in their nature to tip the balance in the favor of the groups and materials that they like and wish for. Governments are not made for the benefit of humanity as a whole - they are made for the citizens of their countries, and even then, for mostly exploitive reasons.

Many participants (6) mentioned the choice of course material and its content in relation to how hidden messages are given in texts or pictures chosen.

\footnotetext{
Although among all the institutions that change drastically with changing governments, education should be the most neutral one that is supposed to remain apolitical, it is the one that is affected most unfortunately. Mandatory courses are determined according to the dominant political trends.
}

One participant referred to the Tevhid-I Tedrisad (Unification in education) reforms supporting the mandatory Turkish courses, in a country where the minority schools had been free to have languages other than Turkish as the medium of instruction. The participant emphasized the unification power of standard and state-funded education institutions, and discussed the democracy package, the recent laws enacted in Turkey that allow minority languages to be offered as elective courses at state schools. The student stated that instead of actually solving problems about education, politicians 
benefit from making propaganda in their messages promising to address these problems. One other participant cited a quotation from Milan Kundera to reveal his ideas on the relation between politics and education drawing attention to how educational policies can be discriminating in practice.

Some participants (3) emphasized the importance of political decisions in English language courses. In Turkey English became popular especially after Turkey became a member of NATO, after the 1950s and the need for its citizens to speak and internationally accepted lingua franca grew exponentially with the spread of English in business and education related interactions.

Today the need to teach and learn English is not because people need to certify their level of English in written multiple choice exams, accordingly the text books used at schools have started attaching more importance to communication oriented activities, still they are ignored and disregarded since the national standard exams do not test one's communication skills in English.

All the participants agreed that the ideas discussed in the seminars did not teach them content knowledge directly but made them think about the system, its foundation principles and who the decision makers were, and who they should be. The majority of the participants related the seminar discussion topics to the Educational Psychology and Educational Sociology courses they were taking alongside the Spoken English course. One expression from the interviews that represents the other students' comments was "I take these ideas and form new ideas; I look at how the political system works in a much different way now".

It is also worth mentioning that students during both the class discussions and the interviews made references to the education policies of other countries such as those in South Korea, China, the USA, Russia, Finland, Burkina Faso, and Germany. While the university that the research was conducted in is an international university, an unusually high number of students participated who did not have a Turkish state school background. The international students contributed in the discussions bringing up the policies in their countries which helped raise awareness in students to understand that Turkey is not unique in having educational policies that change frequently.

\subsection{Critical Awareness in Education and Economics}

The role funding plays in education and English language teaching was another recurring theme. Students made comments revealing their awareness on how publishing companies might play a role when deciding on the materials to be selected to be used in an educational institution, or when changing the materials used. Participants also claimed that while renowned publishing companies may provide Turkish tertiary education institutions with professionally prepared course materials, unless the course books in question are not required by a private university it is very difficult for an average Turkish student to be able afford them, which results in the widespread use of pirated copies. 
The participants stated that in English language teaching settings, the financial background of the families of students may stand out as a discriminating factor much more than it might in other courses since how often a student can find the opportunity to meet speakers of other languages to practice English is highly dependent on how often they can travel abroad, whether they have access and means to not only authentic materials in the target language but also other international socializing events in their country, mobility programs, or leisure travel opportunities.

One student particularly emphasized the importance of being able to join events that would enhance target language practice depending on the cost, and being excluded from certain cliques of students based on their financial background. The intentions of the events may in such cases, the student reported, result in a negative consequence, the isolation of financially limited or less disadvantaged students. Hence success in L2 may be directly related to how opportunities are supported to develop one's target language.

Another student referred to second language cram schools being wide spread in Turkey, but being accessible only to those who can afford to pay for these courses. Hence this has consequences in the university placement exam for those students who would like to take the second language part of the exam with the intentions of being placed at a language teacher training program, translation, literature or linguistics undergraduate program by the national Measuring, Selection and Placement Center (OSYM).

One common recurring theme in the interviews with reference to the relevance of economics to especially English language education in Turkey was that those students from disadvantaged groups with limited access to materials and opportunities that would help develop one's second language are discriminated against and are otherised in language classrooms because of their low proficiency levels, and also because of their heavy accents.

\subsection{Critical Awareness on Education and Cultural diversity}

The participants in the study displayed a very sensitive attitude in the interviews conducted at the end of the academic year after the intervention, yet according to the observation notes and the first interviews, the participants were very open-minded and aware of issues concerning cultural diversity at the beginning of the academic year as well. What were dramatically different are the specific details they referred to in the interviews conducted at the end of the academic year. While in the first interviews the participants emphasized that the teacher should be well aware of diversity in the classroom and should respect students equally, in the second interviews their answers referred to materials and the methodology used in language courses, the unique multicultural atmosphere or structure of a language classroom even when there are no international students in the class, and the oppressive mainstream culture's dominance of minority groups' culture. 


\subsubsection{Materials and the methodology used in language courses}

The topic of culture playing a significant role in the methods and approaches to education was dealt with from different perspectives. Students referred to culture being a determinant in the process of instruction. Especially the four foreign students referred to how cultural norms and expectations are visible not only in the selection of course content material but also in the format of the classroom tasks, and in the attitudes of instructors and expectations from students. One of the participants stated that:

All cultures have their own socially accepted approach to education, and it plays a huge role in the classroom. Everything starting from the curriculum is adapted to that culture. As a foreigner who has studied in an environment where the mainstream culture is not my own, I can surely say that mainstream culture is always dominant not only in the curriculum but in the classroom activities too and is visible even in the attitudes teachers have towards students.

Also about methodology of teaching, a representative answer from one of the participants stated that teachers used different teaching strategies especially in the English classes, a popular one being performance based activities, such as drama, presentations, and group work. Teacher as the transmitter of information concept was still the underlying belief but student tasks in language classes had diversity and this affected the perception of not only the language class, but also what one can do using English as a medium. Hence a journey to other cultures than their own was made possible thanks to the methodology of the English language courses, the participants said.

\subsubsection{The unique multicultural atmosphere or structure of a language classroom}

The English language classroom is thought to differ to a major extent from other courses, as stated by one of the participants:

As everything is usually adapted to the mainstream culture, the individuals play a submissive role. They are expected to learn more about the mainstream culture however; since it is a language classroom we are talking about I do believe that it should be more accepting.

Students assigned a different place to the language class, because of its being a door to other worlds. A language class, especially the English class is expected to be more tolerant towards different cultures, making its students less judgmental and hence more accepting, letting them out of their cocoons and bridging their perceptions with those of the rest of the world. One of the participants suggested:

in a language class multiculturalism is a prerequisite. Although the class can have most of its members from local cultural backgrounds, and the dominant culture can be influencing the agreed on social norms, students still find the opportunity to be exposed to the social norms of other cultures they see in the course materials. It is more likely for them to change. Everything they read or listen to or watch in the English class will be contributing to their 
cultural background. An English class is actually an opportunity to be much less constrained by the culture you are born into.

\subsubsection{Developing inclusive attitudes towards different ethnic or religious backgrounds}

The participants very frequently referred to culture-related discriminatory practices for the relatively less dominant groups in educational settings in the interviews and during their performance in the intervention.

The interviews revealed that the participants' perception of the mainstream culture was a discriminating one. They stated that the mainstream culture stands out to be the dominant one and minority or different variants of the mainstream culture dominant in the educational setting are otherised to the disadvantage of the individuals belonging to those groups such as the case of Alevi Muslims in Turkey, atheists, Armenians or Caucasians or Kurds. Of the 22 participants 15 of them made comments during the interviews specifically referring to how they think the dominant conventional Sunni Muslim Turkish culture alienated and otherised those that belonged to ethnic and other minorities in educational settings. Interestingly, financially less advantaged groups were rarely referred to by the students. The participants made sure that they expressed their discontent with their own educational background but did not think that discrimination against minorities was a Turkey-specific issue. One student, for example gave examples from Norwegian schools in Oslo where students were placed in classes according to their race. Another student gave racist practices at educational institutions in the USA. It was impressive to see students relate their experience to the rest of the world. This revealed a critical awareness of oppression in diverse cases from all around the world. Students did not think that Turkey was unusually a different case; to the contrary among the other countries they referred to the developed countries as well. Another student stated that nationalism sometimes unintentionally caused racism giving examples from fights between ethnic groups in her high school which was well known to emphasize nationalism in every opportunity during the school day. Many participants (10) said that Kurdish friends were exposed to different treatment at school by their 'nationalist' teachers. One Albanian origin student was discouraged from saying that she was an Albanian at school and she used to state that she was Turkish first when talking about cultural rituals. Similarly, some participants (2) referred to the unfair practice of having to speak Turkish only at school even when they could not speak Turkish when they first started primary school. One student was given a round of applause when he said that he wanted to learn Kurdish just to be able to reach out to the students he is teaching if he is appointed by the state to teach in a Kurdish area. Another participant said that she was actually willing to be appointed to a school in the east of Turkey which is a rare case considering that the standards of living might be much different compared to the western part of Turkey. Many participants stated that they would like to be very sensitive not to be discriminating against people from different ethnic backgrounds that they might have prejudices against. One of the participants said that "I now understand how difference can be a negative feature, I am trying to break down all the prejudices I have about people." 
Another participant said that "I did not know that I was lucky enough to receive education in my native tongue." Another participant similarly stated that some students spend the first year of primary school trying to learn Turkish.

There were 6 students who referred specifically to the discrimination shown to people with different attitudes to religion than the majority Sunni Muslim one in Turkey. One of the foreign students expressed that he could not believe that religion courses are state-mandated courses in Turkey disregarding the religious belief of the families of students. One of the participants commented on how a language class would be affected by discriminatory practices:

\footnotetext{
The individual features of the majority in a language classroom can either reduce or increase the effects of hidden curriculum in education. As an example, if the majority of the students in a language classroom don't believe in the mainstream religion, there will be an emphasis on the idea that "it's a matter of religious beliefs" when the teacher has to talk about topics that are related to religion. On the other hand, if the majority believes in the same religion, the teacher would make sentences such as 'We believe in our religion and we should protect these values'.
}

Another student blamed the school system for 'not respecting non-believers.' Another participant expressed that even at tertiary level education when they were choosing a topic of conflict in educational institutions for the role play task, they hesitated to deal with a conflict about the attitude towards religion at Turkish schools. Such statements reveal an awareness of the status quo and a need for change. Another participant stated that especially Alevis are considered to believe in what is wrong, they are considered to be outcasts, but actually they should be able to talk freely about their rituals or understanding, or religion should not be a required course at all at schools. 4 other students also made comments on how the education system is not fair to Alevis and how they are constantly criticized.

Participants referred to multiple aspects of otherizing practices in educational institutions and were seen to have developed a sensitive and more open-minded and tolerant perspective. Education can be a means to widen horizons yet, it is common to see it be a reinforcing power that transmits the mainstream culture to the next generation. It is therefore essential that university students are given courses that focus on critical awareness raising content.

\section{Discussion and Conclusion}

Previous research on critical thinking following a quantitative methodology vary in their focus. Crookes and Al Lehner (1998) provide suggestions related to the classroom processes of critical pedagogy. Tasks that focus particularly on the historical and sociopolitical context of schooling constitute the main focus of their suggestions. In the present study too, such tasks were designed to trigger critical awareness. Socratic seminars were based on input from videos of selected motivational talks on financial and cultural challenges in different educational settings that were discussed thoroughly throughout one academic year. Crookes and Lehner (1998) claim that ESL 
or EFL teachers contribute to general welfare by helping people communicate. While teachers are not encouraged to address sociopolitical issues, the principles of critical pedagogy can easily be integrated into ESL/ EFL teaching. The intervention in the present study aimed at having students address sociopolitical issues. The principles of critical pedagogy were emphasized by presenting classroom situations to problematize, perceive, reflect and act on, thus relating the content of courses to real life. These principles constitute the core principles of critical content integration in the FLE course analyzed in the present study which was underpinned by the belief that the ultimate goal of education is to make a change in society at large. One of the most significant conclusions of the study Crookes and $\mathrm{Al}$ Lehner conducted was that the pessimism of the students who were engaged in a critical pedagogy-driven training program was challenged because pedagogy of possibility was emphasized. Similarly, in the present study, the videos chosen for discussions addressed hardships that teachers with limited means had to overcome, and they all suggested that change was a possibility. The videos about success stories in challenged educational circumstances were considered using a questioning approach in the Socratic seminars that aimed to help students towards understanding the struggle of others. The aim of the present study was to observe the effect of integrating a critical pedagogy-driven program in the Spoken English course offered to pre-service teachers. It was concluded that students were able to problematize education-related issues, perceived them in relation to multiple real life aspects and raised their critical awareness. The participants analyzed the present state of discriminatory practices and suggested a more inclusive approach.

Choy and Cheah, in their article on teachers' perceptions of critical thinking among students, concludes that teachers' perceptions influence students' behaviors, however teachers assume that the presentation of the content, and focusing on the comprehension of the subject matter would suffice to promote the development of critical thinking (Choy \& Cheah, 2009). Although some researchers support the idea that thinking is a naturally evolving skill and thinking critically cannot be taught (Sternberg \& Williams, 2002), there is ample literature which supports that provided the triggering factors to avoid biased, distorted and partial and uninformed rhetoric, students' critical thinking skills will be enhanced, that is they will have an improved cognitive ability to open-mindedly raise questions, analyze, synthesize and evaluate (Duron, Limbach, \& Waugh, 2006; Black, 2005; Nickerson, 1994). The present research concludes that students' ability to analyze critical pedagogical issues triggered their critical thinking skills. In comparison to the interviews conducted at the beginning of the academic year and the observation notes of the researcher, the participants made references to specific economic, political and cultural aspects of their background and they have developed their skills to question and problematize discriminatory practices. The participants' evaluations were much more specific, and their attitude towards the otherised groups revealed a deeper understanding of the struggle of the other at the end of the intervention.

The literature on the role of the teaching method on triggering critical thinking provides different conclusions. Behar-Horenstein and Niu (2011) reviewed 42 empirical 
studies and concluded that it is possible for the same instructional interventions to lead to different results which are not easily captured by quantitative data. BeharHorenstein and Niu also refer to the fact that few studies have focused on developing a critical insight in higher educational settings. The present study chose to use qualitative data analysis tools to be able to capture a contextualized and situated analysis, and concluded that the methodology used bears an undeniable significance in the instructional intervention to lead to the results reached. Critical awareness is found to be triggered through questioning the present practices, approaching them with a critical perspective, and analyzing the problem from political, economic and cultural perspectives. Developing critical awareness is fundamental not only for teacher candidates but also for any student who is to contribute to a civilized society. Hence, with Socratic pedagogy, the urge to question the seemingly known facts to reach a deeper insight has been found to be very beneficial in this particular program. Future research on similar interventions is highly advised to implement Socratic methods into educational programs so that students are engaged in their own education process, and can deduce their own conclusions having considered specific problems from multiple perspectives.

As one of the major implications of this study, especially in language proficiency courses in English Language Teaching departments, pedagogical content integration can be suggested. Critical pedagogical content integration would engage teacher candidates in a reflexive process, which would allow them to understand their teaching context and make decisions on their teaching preferences (Dikilitas, Wyatt, Burns, \& Barkhuizen, 2019). Pedagogical content that raises an awareness of real life teaching circumstances would make an invaluable contribution to the student teachers' fledgling teacher identity. The freshman students studying at the foreign language teacher training programs can start developing a sensitive attitude towards the economic, politic and cultural background of teaching a second language, a lingua franca in their own contexts, make comparative studies with the curricula adopted in other countries, and can discuss the contextual reasoning behind the decisions made on teaching L2 in state and private schools; state and private, first language and English-medium universities. It is hoped that this research is an inspiration for future initiatives aiming at developing critical consciousness, hence would be disseminating a more equity and social justice oriented educational perspective.

\section{References}

Altorf, H. M. (2016). Dialogue and discussion: Reflections on a Socratic method. Arts and Humanities in Higher Education, 18(1), 60-75. doi: 10.1177/1474022216670607

Antonek, J. L., McCormick, D. E., \& Donato, R. (1997). The Student Teacher Portfolio as autobiography: Developing a professional identity. The Modern Language Journal, 81(1), 15. doi: $10.2307 / 329158$

Balbay, S., Pamuk, İ., Temir, T., \& Doğan, C. (2018). Issues in pre-service and in-service teacher training programs for university English instructors in Turkey. Journal of Language and Linguistic Studies, 14(2), 48-60. 
Bartlett, R. C. (2008). Masters of Greek Thought: Plato, Socrates, And Aristotle [Audiobook]. Retrieved from https://www.thegreatcourses.com/courses/masters-of-greekthought-plato-socrates-and-aristotle.html

Bartolome, L. (1994). Beyond the methods fetish: Toward a humanizing pedagogy. Harvard Educational Review, 64, 173-194.

Behar-Horenstein, L. S., \& Niu, L. (2011). Teaching critical thinking skills in higher education: A review of the literature. Journal of College Teaching \& Learning, 8(2). doi: 10.19030/tlc.v8i2.3554

Beltman, S., Glass, C., Dinham, J., Chalk, B., \& Nguyen, B. (2015). Drawing identity: Beginning pre-service teachers' professional identities. Issues in Educational Research, 25(3), 225-245.

Bhaerman, R. D. (1970). The oral/written Socratic Method. Improving college and university teaching, 18(2), 126-128. doi: 10.1080/00193089.1970.10532954

Black, S. (2005). Teaching students to think critically. The Education Digest, 70(6), 42-47.

Boghossian, P. (2002). The Socratic Method (Having a right to get stoned). Teaching Philosophy, 25(4), 345-359. doi: 10.5840/teachphil200225443

Boghossian, P. (2006). Behaviorism, Constructivism, and Socratic Pedagogy. Educational Philosophy and Theory, 38(6), 713-722. doi: 10.1111/j.1469-5812.2006.00226.x

Borren, M. (2013). A sense of the world: Hannah Arendt's hermeneutic phenomenology of common sense. International Journal of Philosophical Studies 21(2), 225-255.

Brott, P.E. \& Kajs, L.T. (2001). Developing the professional identity of first-year teachers through a 'Working Alliance'. Retrieved August 10, 2019, from http://www.altteachercert.org/Working\%20Alliance.html

Chapelle, C. A., \& Duff, P. A. (2003). Some Guidelines for Conducting Quantitative and Qualitative Research in TESOL. TESOL Quarterly, 37(1), 157-178. doi: 10.2307/3588471

Chong, S., Low, E. L., \& Goh, K. C. (2011). Developing student teachers' professional identities - An exploratory study. International Education Studies, 4(1), 30-38. doi: 10.5539/ies.v4n1p30

Choy, S. C., \& Cheah, P. K. (2009). Teacher perceptions of critical thinking among students and its influence on higher education. International Journal of Teaching and Learning in Higher Education, 20(2), 198-206.

Crawford, L. M. (1978). Paulo Freire's philosophy: Derivation of curricular principles and their application to second language curriculum design (Unpublished doctoral dissertation). University of Minnesota, Minneapolis.

Crookes, G., \& Lehner, A. (1998). Aspects of process in an ESL critical pedagogy teacher education course. TESOL Quarterly, 32(2), 319. doi: 10.2307/3587586

Dikilitas, K., Wyatt, M., Burns, A., \& Barkhuizen, G. (2019). Energising Teacher Research. Kent: IATEFL.

Duron, R., Limbach, B., \& Waugh, W. (2006). Critical thinking framework for any discipline. International Journal of Teaching and Learning in Higher Education, 17(2), 160166.

Ennis, R. H. (1989). Critical thinking and subject specificity: Clarification and needed research. Educational Researcher, 18(3), 4-10.

Filkins, S. (n.d.). Strategy Guide: Socratic Seminars. Retrieved February 6, 2019, from http://www.readwritethink.org/professional-development/strategy-guides/socraticseminars-30600.html

Freire, P. (2005). The banking concept of education. In D. Bartholomae, \& A. Petrosky, Ways of reading. (7th ed.). New York: St. Martin's Press. 
Gratch, A. (2001). The culture of teaching and beginning teacher development. Teacher Education Quarterly, 28(4), 121-136.

Kelchtermans, G., \& Ballet, K. (2002). The Micropolitics of teacher induction: A narrativebiographical study on teacher socialization. Teaching and Teacher Education, 18, 105120. doi: 10.1016/S0742-051X(01)00053-1

Kırkgöz, Y. (2017). English education policy in Turkey. In English language education policy in the Middle East and North Africa (pp. 235-256). Cham, Switzerland: Springer.

Kırkgöz, Y., Çelik, S. \& Arıkan, A. (2016). Laying the theoretical and practical foundations for a new elementary English curriculum in Turkey: A procedural analysis. Kastamonu Education Journal 24(3), 1199-1212.

Madison, D. S. (2005). Critical ethnography: Methods, ethics, and performance. Thousand Oaks, CA: Sage.

Mayer, J. (1986). Teaching critical awareness in an introductory course. Teaching Sociology, 14(4), 249-256. doi: 10.2307/1318382

McNamara, T. (2012). Poststructuralism and its challenges for applied linguistics. Applied Linguistics, 33(5), 473-482.

Morrow, R. A., \& Brown, D. D. (1994). Critical theory and methodology. Thousand Oaks, CA: Sage

Nelson, L. (2004). 'The Socratic Method'. R. Saran \& B. Neiser (eds.). Enquiring Minds: Socratic Dialogue in Education. Stoke on Trent: Trentham, 126-165.

Nickerson, R. S. (1994). The teaching of thinking and problem solving. In R. J. Sternberg (Ed.), Thinking and problem solving (pp. 121-132). San Diego: Academic Press.

Lee, I. (2007). Preparing pre-service English teachers for reflective practice. ELT Journal, 61(4), 321-329. doi: 10.1093/elt/ccm022

Pennycook, A. (1994). Critical pedagogical approaches to research. TESOL Quarterly, 28(4), 690693.

Schwarze, S. \& Lape, H. (2000). Thinking Socratically: critical thinking about everyday issues (2nd edn.). New York, Prentice Hall.

Sternberg, R. J., \& Williams, W. M. (2002). Educational psychology. Boston: Allyn and Bacon.

The six types of Socratic questions. (n.d.). Retrieved February 12, 2019, from http://www.umich.edu/ elements/probsolv/strategy/cthinking.htm

Osam, U. V. \& Balbay, S. (2004). Investigating the decision-making skills of cooperating teachers and student teachers of English in a Turkish context. Teaching and Teacher Education. 20, 745-758.

Valli, L. (1997). Listening to other voices: A description of teacher reflection in the United States. Peabody Journal of Education, 72(1), 67-88. doi: 10.1207/s15327930pje7201_4

\section{Appendix. Interview questions}

\section{First interview questions:}

- What do you think about the pedagogical content of the course?

- Have you benefited from the content of the discussions? If so, in what ways? Do you vision yourself as a teacher already?

- Do you have a clear vision of yourself as a teacher?

- Have you noticed a change in your perceptions on the teaching profession this semester? 
- Do you think politics has a major role in education?

- Would you like to incorporate political issues in your language classroom?

- Do you think issues related to discriminatory practices on class, gender, age, ethnic background, religion, sexual orientation, and the like have a place in the language classroom?

- Do you think it is possible for you as a teacher to be rid of all kinds of prejudices?

- Do you believe that a language teacher should have a mission to make a change in the world?

Second interview questions:

- What do you think is the role of the dominant ideology of the teaching context in language classrooms?

- What do you think is the role of the mainstream culture in language classrooms?

- What do you think is the role of the individual features (ethnic background, class, race, gender, age) of the majority in a class in language classrooms?

- What do you think about the place of oppressed groups in education, and educational materials?

- Do you think students are discriminated in educational institutions according to their class, ethnic background, sexual orientation, religion, native language, etc.? Please refer to specific examples from your experience or observations.

- Do you vision your future professional self-capable of not discriminating among students according to their backgrounds?

- Have you noticed a change in your perceptions on the teaching profession this academic year?

- If you have, what has been most influential in your perceptions? Please refer to specific content, tasks or people in the course.

- Do you vision yourself as a teacher who can make a change in issues that you do not approve of in educational contexts?

- Have you become more careful with your language use when referring to 'otherized' groups this semester?

\section{Copyrights}

Copyright for this article is retained by the author(s), with first publication rights granted to the Journal.

This is an open-access article distributed under the terms and conditions of the Creative Commons Attribution license (CC BY-NC-ND) (http://creativecommons.org/licenses/by-nc-nd/4.0/). 